\title{
Polyaniline nanosheet derived B/N co-doped carbon nanosheets as efficient metal-free catalysts for oxygen reduction reaction $\dagger$
}

Cite this: J. Mater. Chem. A, 2014, 2, 7742

Received 16th February 2014 Accepted 27th March 2014

DOI: $10.1039 / c 4 t a 00814 f$

\author{
Yi Zhang, $\star^{\mathrm{ab}}$ Xiaodong Zhuang, $\star^{\mathrm{b}}$ Yuezeng Su, ${ }^{\text {*a }}$ Fan Zhang ${ }^{\star \mathrm{b}}$ and Xinliang Feng ${ }^{\mathrm{bc}}$
}

www.rsc.org/MaterialsA

A novel B/N co-doped porous carbon nanosheet with a high heteroatom doping content has been successfully prepared. Using amino-functionalized graphene oxide (GO) as the template, oxidation polymerization of aniline, 3-aminophenylboronic acid, and $m$-phenylenediamine generates GO-based polyaniline nanosheets functionalized with boronic acid (GO-CBP). After high-temperature treatment, graphene-based B/N co-doped carbon nanosheets (G-CBP) are obtained, which show a typical 2D morphology with a thickness of $\sim 20 \mathrm{~nm}$. After $\mathrm{CO}_{2}$ activation at $1000^{\circ} \mathrm{C}$, the obtained porous carbon nanosheets (G-CBP-a) have a thickness of $\sim 17 \mathrm{~nm}$ and a high specific surface area of $363 \mathrm{~m}^{2} \mathrm{~g}^{-1}$. Benefiting from its high surface area, unique $2 \mathrm{D}$ sheet nanostructure, and high heteroatom-doping contents $(5.4 \% \mathrm{~B}$ and $5.3 \% \mathrm{~N}$ ), G-CBP-a exhibits excellent electrochemical performance for the oxygen reduction reaction under alkaline conditions $(0.1 \mathrm{M}$ $\mathrm{KOH})$, with a low half-wave potential $(-0.27 \mathrm{~V}$ for G-CBP-a versus $-0.18 \mathrm{~V}$ for $\mathrm{Pt} / \mathrm{C}$ ), a dominant four-electron transfer mechanism ( $n=$ 3.78 at $-0.45 \mathrm{~V})$, and excellent methanol tolerance and durability $(10 \%$ current decrease after 20000 s operation), as well as a high diffusionlimiting current density $\left(\mathrm{J}_{\mathrm{L}}=-4.5 \mathrm{~mA} \mathrm{~cm}^{-2}\right)$.

\section{Introduction}

In the belief that they are the most feasible $\mathrm{Pt}$ alternatives, heteroatom $\left(N,{ }^{1-5} \mathrm{~B},{ }^{6,7} \mathrm{~S},{ }^{8} \mathrm{P}^{9}\right)$-doped carbon materials have attracted remarkable attention as metal-free catalysts for oxygen reduction reaction (ORR), which is the key process in fuel cells. The doped carbon catalysts show better fuel cross-over

${ }^{a}$ School of Aeronautics and Astronautics, Shanghai Jiao Tong University, Shanghai 200240, China.E-mail: yzsu@sjtu.edu.cn

${ }^{b}$ School of Chemistry and Chemical Engineering, Shanghai Jiao Tong University, Shanghai 200240, China. E-mail:fan-zhang@sjtu.edu.cn

${ }^{c}$ Max Planck Institute for Polymer Research, Ackermannweg 10, D-55128 Mainz, Germany

$\dagger$ Electronic supplementary information (ESI) available: Experimental details; SEM and TEM of AGO; FTIR and TGA; XPS spectra of GO-CBP; some electrochemical data. See DOI: 10.1039/c4ta00814f

\$ These two authors contributed equally to this work. resistance and long-term durability than commercially available $\mathrm{Pt} / \mathrm{C}$ in an alkaline medium. However, the doped carbons generally exhibit inferior performance with respect to half-wave potential, diffusion-limiting current, and kinetic current density. Experimental results and theoretical calculations $\mathbf{s}^{\mathbf{6} 10-12}$ suggest that two key factors are responsible for the pronounced ORR performance of heteroatom-doped carbon materials: (1) a tailored $\pi$ electronic system for high conductivity and electron non-neutral sites and (2) porous structures with a high specific surface area for $\mathrm{O}_{2}$ adsorption and conversion. ${ }^{13-17} \mathrm{~A}$ high electron affinity atom such as $\mathrm{N}(\chi=3.04)$ or a low electron affinity atom such as $\mathrm{B}(\chi=2.04)$ can create charged sites in the carbon framework that are favorable for $\mathrm{O}_{2}$ adsorption. In this respect, $\mathrm{B} / \mathrm{N}$ co-doped carbon materials have drawn immense attention because of their unique electronic structures ${ }^{\mathbf{1 0}}$ with a synergistic coupling effect between the heteroatoms. For instance, $\mathrm{B} / \mathrm{N}$ co-doped carbon nanotubes, ${ }^{10,18,19}$ graphene, ${ }^{20}$ and carbon monoliths ${ }^{21}$ have been synthesized that show comparable ORR performance to $\mathrm{Pt} / \mathrm{C}$ regarding fuel cross-over resistance, long-term durability, kinetic limiting current density, and half-wave potential. Despite the successful integration of heteroatoms into the graphene/carbon nanotube lattices, the co-doping method utilizing the in situ pyrolysis of a single precursor is still under development.

Graphene, a two-dimensional aromatic monolayer of carbon atoms, has attracted great attention owing to its exceptional physical, chemical, and mechanical properties, as well as its potential applications in electronics, sensors, supercapacitors, and batteries. ${ }^{22-24}$ Undoubtedly, heteroatom-doped graphene also holds great promise for catalysis. ${ }^{25}$ In addition to the fabrication of doped graphene by chemical vapor deposition ${ }^{\mathbf{2 6}}$ involving a vacuum-based system, which is generally complicated and expensive for large-scale production, there is another strategy for the preparation of doped graphene: the direct pyrolysis of heteroatom-containing precursors with graphene or graphene oxide (GO). ${ }^{27}$

In this work, we present a novel strategy to synthesize $\mathrm{B} / \mathrm{N}$ codoped porous carbon nanosheets with high heteroatom doping 
contents (5.4\% B and 5.3\% N). Using amino-functionalized GO as the template, oxidation polymerization of aniline, 3-aminophenylboronic acid, and the cross-linker $m$-phenylenediamine ${ }^{28}$ generates GO-based polyaniline nanosheets functionalized with boronic acid (GO-CBP). After high-temperature treatment at $1000{ }^{\circ} \mathrm{C}$, the as-produced carbon nanosheets (G-CBP) show a typical 2D morphology with a thickness of about $20 \mathrm{~nm}$. Further activation of G-CBP with $\mathrm{CO}_{2}$ at $1000{ }^{\circ} \mathrm{C}$ yields porous carbon nanosheets (G-CBP-a) with a thickness of $\sim 17 \mathrm{~nm}$ and a high specific surface area of $363 \mathrm{~m}^{2} \mathrm{~g}^{-1}$. Benefiting from the high surface area, the unique $2 \mathrm{D}$ sheet nanostructure, and the high heteroatom-doping contents (5.4\% B and 5.3\% N), G-CBPa exhibits excellent electrochemical performance with respect to the oxygen reduction reaction (ORR) under alkaline conditions (0.1 M KOH), with a low half-wave potential $(-0.27 \mathrm{~V}$ for G-CBPa versus $-0.18 \mathrm{~V}$ for $\mathrm{Pt} / \mathrm{C}$ ), a dominant four-electron transfer mechanism ( $n=3.78$ at $-0.45 \mathrm{~V}$ ), and excellent methanol tolerance and durability $(10 \%$ current decrease after $20000 \mathrm{~s}$ operation), as well as a high diffusion-limiting current density $\left(J_{\mathrm{L}}=-4.5 \mathrm{~mA} \mathrm{~cm}^{-2}\right)$.

\section{Results and discussion}

The typical synthesis route towards G-CBP-a is illustrated in Scheme 1. First, GO nanosheets ${ }^{29}$ were modified with amino groups by the reaction between $p$-phenylenediamine and the carboxyl group on GO in the presence of $N$-hydroxysuccinimide (NHS) and $N$-(3-(dimethylamino)propyl)- $N^{\prime}$-ethylcarbodiimide hydrochloride $(\mathrm{EDC} \cdot \mathrm{HCl})$ as catalysts in dry DMF. Then, the amino-functionalized GO (AGO) was subjected to the in situ oxidation polymerization of the monomer aniline, the crosslinker $m$-phenylenediamine, ${ }^{28}$ and the boron source 3 -aminobenzeneboronic acid hemisulfate salt (ABB). Afterwards, the
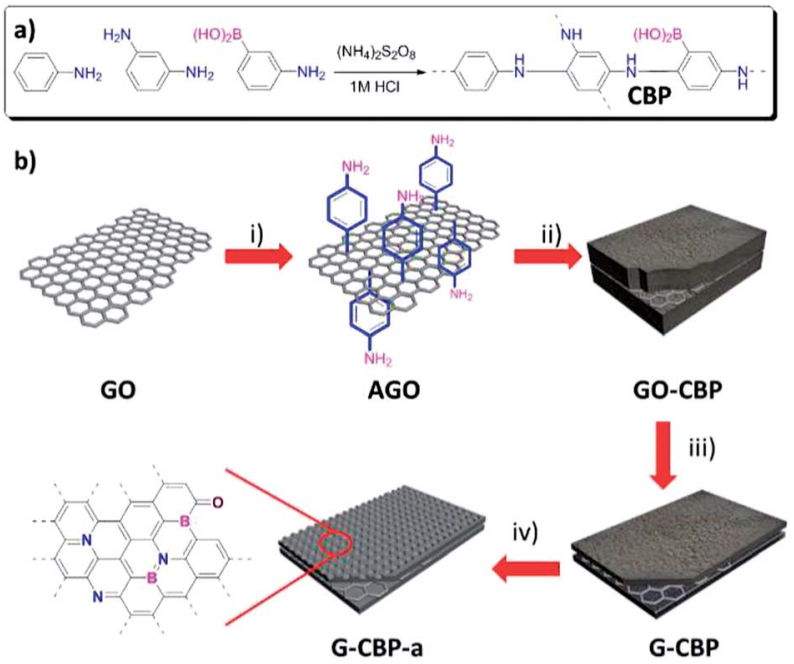

Scheme 1 Preparation of GO-CBP, G-CBP, and G-CBP-a using the amino-functionalized $\mathrm{GO}$ template. (i) $\mathrm{EDC} \cdot \mathrm{HCl}, \mathrm{NHS}$, dry $\mathrm{DMF}, 0^{\circ} \mathrm{C}$ for $2 \mathrm{~h}$, then $\mathrm{p}$-phenylenediamine, $0{ }^{\circ} \mathrm{C}$ for $2 \mathrm{~h}$; (ii) aniline, $\mathrm{m}$-phenylenediamine, $\mathrm{ABB}$, ammonium persulfate, $1 \mathrm{M} \mathrm{HCl}, 0{ }^{\circ} \mathrm{C}$ for $2 \mathrm{~h}$ then RT overnight; (iii) $\mathrm{N}_{2}, \mathrm{RT}$ to $1000^{\circ} \mathrm{C}, 5^{\circ} \mathrm{C} \mathrm{min}{ }^{-1}, 1 \mathrm{~h}$; (iv) $\mathrm{N}_{2}$, RT to 1000 ${ }^{\circ} \mathrm{C}, 5^{\circ} \mathrm{C} \mathrm{min}^{-1}$, then $\mathrm{CO}_{2}, 1000^{\circ} \mathrm{C}, 15 \mathrm{~min}$. obtained GO-based polyaniline nanosheets functionalized with boronic acid (GO-CBP) were pyrolyzed at $1000{ }^{\circ} \mathrm{C}$, affording $\mathrm{B} / \mathrm{N}$ co-doped carbon nanosheets (G-CBP). Finally, after $\mathrm{CO}_{2}$ activation of G-CBP at $1000{ }^{\circ} \mathrm{C}, \mathrm{B} / \mathrm{N}$ co-doped porous carbon nanosheets (G-CBP-a) were produced. A control sample of CBP without utilizing the AGO template was also synthesized under the same conditions.

The morphologies of AGO, GO-CBP, G-CBP, and G-CBP-a were investigated by scanning electron microscopy (SEM), transmission electron microscopy (TEM), and atomic force microscopy (AFM). The SEM image (Fig. S1a $\dagger$ ) shows the typical curved, layer-like feature of AGO, which is similar to that of GO. GO-CBP maintained this 2D morphology, ranging in the sheet size from $200 \mathrm{~nm}$ to several micrometers. Based on the SEM and TEM images in Fig. 1a and b, no free porous polymer particles or naked graphene sheets were observed, indicating that most of the monomers were polymerized on the surface of AGO. The AFM image further revealed the same 2D morphology observed in the SEM and TEM images (Fig. 1c). After pyrolysis, G-CBP exhibited a typical 2D sheet nanostructure (Fig. 1d and e), similar to that of GO-CBP. After $\mathrm{CO}_{2}$ activation at $1000{ }^{\circ} \mathrm{C}$, G-CBP-a also exhibited a flexible and crumpled morphology similar to that of GO-CBP and G-CBP (TEM images in Fig. 1b, e, and h). Further, GO-CBP, G-CBP, and G-CBP-a had average thicknesses of $\sim 30, \sim 20$, and $\sim 17 \mathrm{~nm}$, respectively. The decreased thickness of G-CBP can be attributed to the thermal treatment, which caused decomposition and recombination of the carbon framework, while the thickness decrease caused by $\mathrm{CO}_{2}$ activation should be ascribed to the reduction reaction between $\mathrm{CO}_{2}$ and carbon at high temperature.

Fourier transform infrared (FT-IR) spectra of CBP, AGO, and GO-CBP are shown in Fig. S2. $\dagger$ The characteristic peaks from the FT-IR spectrum of GO-CBP at 1612 and $1507 \mathrm{~cm}^{-1}$ correspond to the $\mathrm{C}-\mathrm{C}$ stretching vibration of the quinoid ring and the benzenoid ring, respectively. ${ }^{30}$ Asymmetric B-O stretching was observed at $1412 \mathrm{~cm}^{-1} \cdot{ }^{31}$ The thermal stability of CBP and
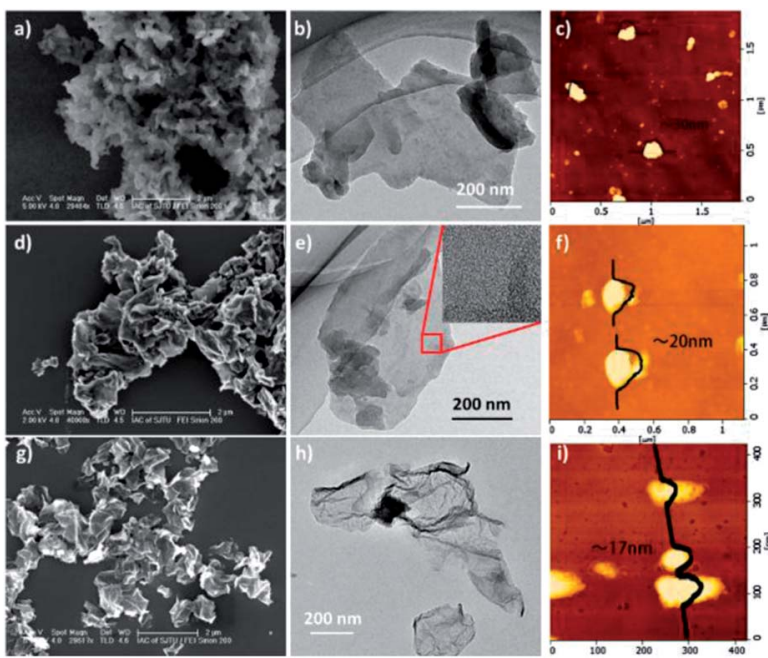

Fig. $1 \operatorname{SEM}(a, d$, and g), TEM (b, e, and $h)$, and AFM (d, $f$, and i) images of GO-CBP ( $a, b$, and c), G-CBP (d, e, and f), and G-CBP-a (g, h, and i). 
GO-CBP was further studied by thermogravimetric analysis (TGA). As shown in Fig. S3, $\dagger$ the weight loss of GO-CBP $(21 \%)$ is less than that of CBP $(24 \%)$ at $400{ }^{\circ} \mathrm{C}$. The residue from GO-CBP had the highest weight (50\%) compared with that from CBP $(47 \%)$ and AGO $(42 \%)$ at $800{ }^{\circ} \mathrm{C}$. This result suggests that incorporation of the graphene layer within polyaniline enhances the thermal stability of the composite.

The porous nature of GO-CBP, G-CBP, and G-CBP-a was evaluated by nitrogen physisorption measurements. The pore size distribution and specific surface area were calculated from the adsorption isotherms based on the nonlocal density functional theory (NL-DFT) and Brunauer-Emmett-Teller (BET) methods. It was found that the isotherms of GO-CBP, G-CBP, and G-CBP-a were type III according to the IUPAC classification. ${ }^{32}$ A significant increase in the adsorption isotherm when the relative pressure was beyond 0.95 implied the presence of meso/macropores in the samples. A small hysteresis loop at a relative pressure of $0.4-0.95$ was observed, indicating the presence of silt pores. ${ }^{32}$ The pore size distributions of GO-CBP, G-CBP, and G-CBP-a are presented in Fig. 3b. G-CBP and G-CBPa show peaks at around $1.5,3.0$, and $4.1 \mathrm{~nm}$, suggesting the presence of numerous micro/mesopores. The detailed results are summarized in Table 1. The BET surface areas of GO-CBP, G-CBP, and G-CBP-a were calculated to be 39,110 , and $363 \mathrm{~m}^{2}$ $\mathrm{g}^{-1}$, respectively. The total pore volume of G-CBP-a reached $1.58 \mathrm{~cm}^{3} \mathrm{~g}^{-1}$, which is more than twice that of G-CBP $\left(0.664 \mathrm{~cm}^{3}\right.$ $\left.\mathrm{g}^{-1}\right)$. The high specific surface area and pore volume of G-CBP-a with respect to G-CBP can be explained by the drastic reaction between carbon and $\mathrm{CO}_{2}$ at high temperature which produces $\mathrm{CO}$ and creates rich micro- and mesopores $(1.5,2.5$, and $3.4 \mathrm{~nm}$ in Fig. 2b). ${ }^{33}$

X-ray photoelectron spectroscopy (XPS) was further used to investigate the chemical nature of GO-CBP, G-CBP, and G-CBP-a (Fig. S4 $\uparrow$ and 3). The boron and nitrogen components that were calculated from the XPS results are listed in Table 1. G-CBP has a higher nitrogen content $(10.4 \%)$ than G-CBP-a $(5.3 \%)$, while the boron content in G-CBP $(2.1 \%)$ is lower than that in G-CBP-a $(5.4 \%)$. This result indicates that boron is more stable than nitrogen in the carbon framework under high temperature and a $\mathrm{CO}_{2}$ atmosphere. As shown in Fig. 3, both the $\mathrm{N} 1 \mathrm{~s}$ and $\mathrm{B} 1 \mathrm{~s}$ spectra of G-CBP and G-CBP-a show similar chemical compositions. The N in G-CBP and G-CBP-a can be fitted by three peaks corresponding to quaternary $\mathrm{N}\left(\mathrm{N}_{1}, 401 \pm 0.1 \mathrm{eV}\right)$, pyridinic $\mathrm{N}$ $\left(\mathrm{N}_{2}, 399.2 \pm 0.1 \mathrm{eV}\right)$, and $\mathrm{N}$ in the $\mathrm{N}-\mathrm{B}-\mathrm{C}$ configuration $\left(\mathrm{N}_{3}\right.$, $398.4 \pm 0.1 \mathrm{eV}) .{ }^{10}$ It can be assumed that the proportion of these
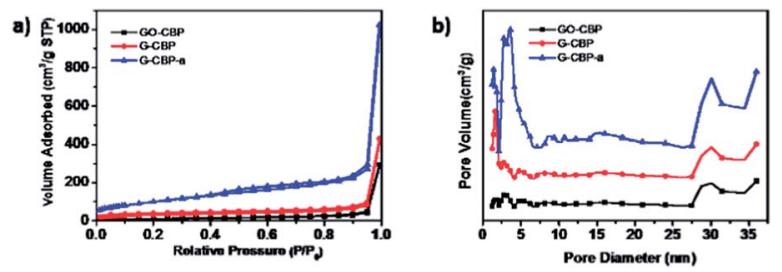

Fig. 2 (a) Nitrogen adsorption/desorption isotherms of GO-CBP, G-CBP, and G-CBP-a. (b) Pore size distributions calculated by the NLDFT method.
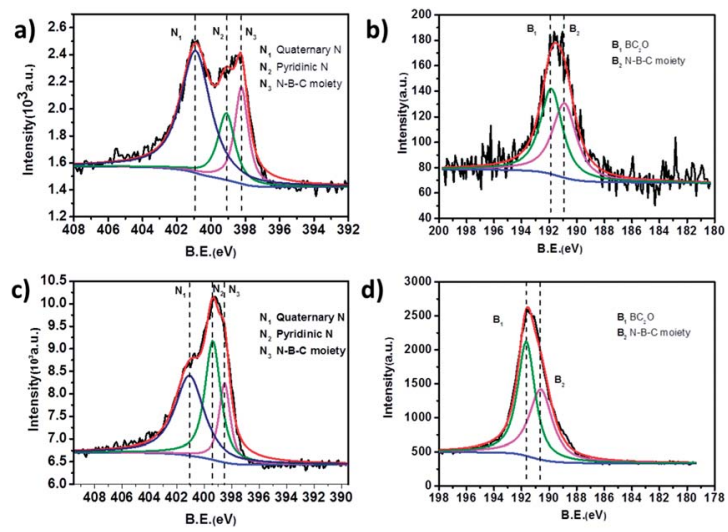

Fig. $3 \mathrm{~N}$ 1s and $\mathrm{B}$ 1s XPS spectra of G-CBP ( $\mathrm{a}$ and $\mathrm{b}$ ) and G-CBP-a (c and d).

Table 1 Surface area, pore volume, pore size, and elemental composition of GO-CBP, G-CBP and G-CBP-a

\begin{tabular}{lcll}
\hline & GO-CBP & G-CBP & G-CBP-a \\
\hline$S_{\text {BET }}{ }^{a}\left(\mathrm{~m}^{2} \mathrm{~g}^{-1}\right)$ & 39.1 & 110.4 & 362.9 \\
$S_{\text {Langmuir }}{ }^{c}\left(\mathrm{~m}^{2} \mathrm{~g}^{-1}\right)$ & 59.1 & 131.9 & 531.2 \\
$V_{\text {tot }}{ }^{c}\left(\mathrm{~cm}^{3} \mathrm{~g}^{-1}\right)$ & 0.456 & 0.664 & 1.58 \\
$d_{\mathrm{av}}{ }^{d}\left(\mathrm{~nm}^{2}\right)$ & 46.7 & 24.0 & 17.1 \\
$\mathrm{~N} \%(\mathrm{wt} \%)$ & 9.71 & 10.4 & 5.3 \\
$\mathrm{~N}_{1} / \mathrm{N}_{2} / \mathrm{N}_{3}{ }^{e}$ & - & $65 / 19 / 16$ & $17.7 / 37 / 45.3$ \\
$\mathrm{~B}(\mathrm{wt} \%)$ & 1.12 & 2.1 & 5.4 \\
$\mathrm{~B}_{1} / \mathrm{B}_{2}^{f}$ & - & $60 / 40$ & $43 / 57$
\end{tabular}

${ }^{a}$ Surface area calculated from the $\mathrm{N}_{2}$ adsorption isotherm using the BET method. ${ }^{b}$ Surface area calculated from the $\mathrm{N}_{2}$ adsorption isotherm using the Langmuir method. ${ }^{c}$ Total pore volume at $p / p_{0}=$ 0.99 . ${ }^{d}$ Average pore size for $p / p_{0}$ between 0.05 and $0.99 .{ }^{e} \mathrm{~N}_{1}, \mathrm{~N}_{2}$, and $\mathrm{N}_{3}$ correspond to quaternary $\mathrm{N}$, pyridinic $\mathrm{N}$ and the $\mathrm{N}$ in the $\mathrm{N}-\mathrm{B}-\mathrm{C}$ moiety, respectively. ${ }^{f} \mathrm{~B}_{1}$ and $\mathrm{B}_{2}$ correspond to the $\mathrm{B}$ in the $\mathrm{N}-\mathrm{B}-\mathrm{C}$ moiety and in $\mathrm{BC}_{2} \mathrm{O}$, respectively.

nitrogen components exhibited a great change before and after activation. The $\mathrm{B}$ in G-CBP and G-CBP-a can be fitted by the $\mathrm{B}-\mathrm{C}=\mathrm{O}^{10}\left(\mathrm{~B}_{1}, 191.9 \pm 0.1 \mathrm{eV}\right)$ and $\mathrm{N}-\mathrm{B}-\mathrm{C}\left(\mathrm{B}_{2}, 190.8 \pm 0.1 \mathrm{eV}\right)$ moieties. ${ }^{10}$ The high percentage of $\mathrm{N}-\mathrm{B}$ bonds $(3.1 \mathrm{wt} \%$ based on $\mathrm{B}_{2}$ ) indicates that nitrogen and boron can be easily coordinated under high-temperature treatment. ${ }^{34}$ The relative content of $\mathrm{B}_{1}$ significantly increased after the activation process, possibly due to the higher reactivity of carbon with $\mathrm{CO}_{2}$ than boron with $\mathrm{CO}_{2}$.

To gain insight into the electrocatalytic behavior of G-CBP-a, we examined the electrocatalytic activities of the $\mathrm{B} / \mathrm{N}$ co-doped porous carbon nanosheets toward the ORR under alkaline conditions $(0.1 \mathrm{M} \mathrm{KOH})$. The ORR catalytic activity of G-CBP and G-CBP-a was first evaluated by cyclic voltammetry (CV) (Fig. 4a) in $\mathrm{N}_{2}$ - and $\mathrm{O}_{2}$-saturated $0.1 \mathrm{M} \mathrm{KOH}$ as well as in $\mathrm{O}_{2}$-saturated 0.1 $\mathrm{M}$ KOH solution with $1.0 \mathrm{M}$ methanol. The oxygen reduction peak for G-CBP-a was observed at $-0.24 \mathrm{~V}$, whereas the signal vanished in $\mathrm{N}_{2}$-saturated $0.1 \mathrm{M} \mathrm{KOH}$. G-CBP exhibited the same phenomenon, while the oxygen reduction peak for G-CBP $(-0.32 \mathrm{~V})$ was more negative than that of G-CBP-a, which indicates higher energy consumption for oxygen reduction. No 
a)

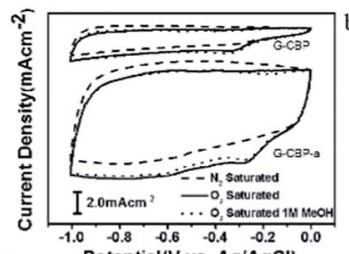

c)
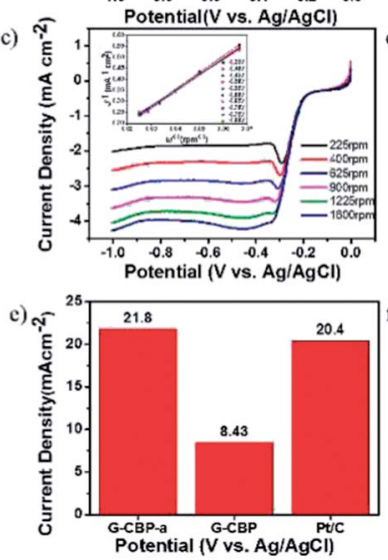
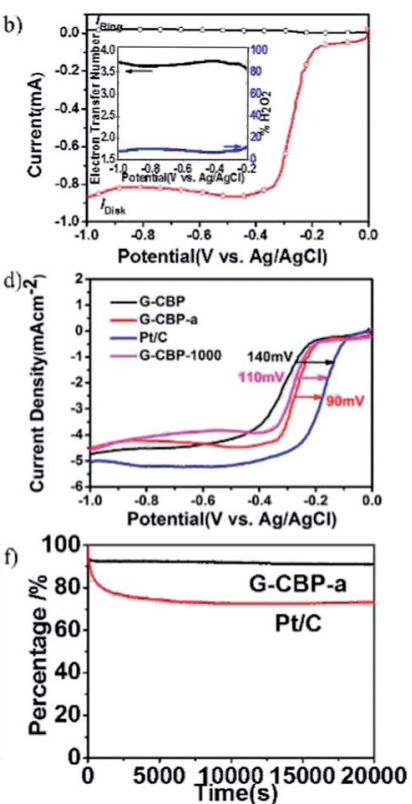

Fig. 4 ORR performance of G-CBP, G-CBP-a, and Pt/C. (a) Typical cyclic voltammograms for G-CBP and CBP-a at a scan rate of $100 \mathrm{mV}$ $\mathrm{s}^{-1}$ in $\mathrm{O}_{2}$ and $\mathrm{N}_{2}$-saturated $0.1 \mathrm{M} \mathrm{KOH}$ solutions as well as in $\mathrm{O}_{2}$ saturated $0.1 \mathrm{M} \mathrm{KOH}$ solution with $1.0 \mathrm{M}$ methanol. (b) RRDE voltammogram for $\mathrm{G}-\mathrm{CBP}-\mathrm{a}$ in $0.1 \mathrm{M} \mathrm{KOH}$ solution saturated with $\mathrm{O}_{2}$; the electrode rotation rate was $1600 \mathrm{rpm}$ and the Pt ring electrode was held at $0.5 \mathrm{~V}$ (inset: electron transfer number and the percentage of $\mathrm{H}_{2} \mathrm{O}_{2}$ as a function of potential). (c) RDE voltammograms for G-CBP-a in $0.1 \mathrm{M} \mathrm{KOH}$ solution saturated with $\mathrm{O}_{2}$ (inset: Koutecky-Levich plots calculated from the RDE result). (d) Oxygen reduction polarization curves for G-CBP, G-CBP-a, G-CBP-1000 and Pt/C on GC electrodes at $1600 \mathrm{rpm}$ in $0.1 \mathrm{M} \mathrm{KOH}$. (e) Calculated kinetic limiting current densities at $-0.45 \mathrm{~V}$ (versus $\mathrm{Ag} / \mathrm{AgCl}$ ) for $\mathrm{G}-\mathrm{CBP}, \mathrm{G}-\mathrm{CBP}-\mathrm{a}$, and $\mathrm{Pt} / \mathrm{C}$. (f) Chronoamperometric responses for $\mathrm{G}-\mathrm{CBP}-\mathrm{a}$ and $\mathrm{Pt} / \mathrm{C}$ at $-0.36 \mathrm{~V}$ in $\mathrm{O}_{2}$-saturated $0.1 \mathrm{M} \mathrm{KOH}$.

noticeable change was observed in the CV results of G-CBP and G-CBP-a in $\mathrm{O}_{2}$-saturated $0.1 \mathrm{M} \mathrm{KOH}$ solution with $1.0 \mathrm{M}$ methanol. This result indicates good methanol tolerance for both G-CBP and G-CBP-a.

To further explore the ORR performance of G-CBP-a, rotating-ring disk electrode (RRDE) voltammetry and rotatingdisk electrode (RDE) voltammetry studies were performed. The onset potential for G-CBP-a in RRDE voltammograms was at approximately $-0.23 \mathrm{~V}$ (Fig. $4 \mathrm{~b}$ ), which is close to that identified from CV measurements $(-0.24 \mathrm{~V}$, Fig. $4 \mathrm{a})$. The onset potentials for G-CBP and Pt/C are -0.25 and $-0.07 \mathrm{~V}$, respectively. The $\mathrm{RDE}$ voltammetric profiles in $\mathrm{O}_{2}$-saturated $0.1 \mathrm{M} \mathrm{KOH}$ solution showed that the current density was enhanced upon increasing the rotation rate (from 225 to 1600 rpm, Fig. 4c). KouteckyLevich (K-L) plots (the inset in Fig. 4c) with a good linear relationship for the G-CBP-a electrode were drawn from the linear sweep voltammetry (LSV) curves (Fig. 4c) at various rotation rates. Linearity and parallelism of the plots are usually taken as an indication of first-order reaction kinetics with respect to the concentration of dissolved $\mathrm{O}_{2}$. According to eqn (S2)-(S4), $\dagger^{1,35}$ the number of transferred electrons $(n)$ and the kinetic current density $\left(J_{\mathrm{K}}\right.$, Fig. 4e) can be calculated from the slope and intercept of the K-L plots, respectively. Notably, the calculated number of transferred electrons $(n)$ per $\mathrm{O}_{2}$ molecule involved in the ORR was 3.78 at $-0.45 \mathrm{~V}$. A similar value of $n(\sim 3.85$ at $-0.45 \mathrm{~V}$ ) can be calculated from the RRDE curve (Fig. $4 \mathrm{~b}$ and eqn (S1) †). ${ }^{36}$ In contrast, the calculated $n$ for G-CBP was only 3.25 at $-0.45 \mathrm{~V}$. These results highlight that, for G-CBP-a, the ORR proceeds via a primary four-electron pathway.

The corresponding LSV curves for G-CBP, G-CBP-a, and Pt/C in an $\mathrm{O}_{2}$-saturated $0.1 \mathrm{M} \mathrm{KOH}$ solution at a rotation rate of 1600 rpm are compared in Fig. 4d. G-CBP-a exhibited a high diffusion-limiting current, reaching $-4.5 \mathrm{~mA} \mathrm{~cm}^{-2}$, which was close to that of $\mathrm{Pt} / \mathrm{C}\left(-5.1 \mathrm{~mA} \mathrm{~cm}^{-2}\right)$. G-CBP showed a relatively low diffusion-limiting current of about $-3.8 \mathrm{~mA} \mathrm{~cm}^{-2}$. Remarkably, G-CBP-a displayed a low half-wave potential at $-0.27 \mathrm{~V}$, which was only $90 \mathrm{mV}$ higher than that of Pt/C (-0.18 V) (Fig. 4d) and $50 \mathrm{mV}$ lower than that of G-CBP. Additionally, the kinetic current density of G-CBP-a $\left(21.8 \mathrm{~mA} \mathrm{~cm}^{-2}\right)$ at $-0.45 \mathrm{~V}$ was slightly higher than that of $\left.\mathrm{Pt} / \mathrm{C}(20.4 \mathrm{~mA} \mathrm{~cm})^{-2}\right)$, and significantly greater than that of G-CBP $\left(8.43 \mathrm{~mA} \mathrm{~cm}^{-2}\right)$. These results clearly reveal the enhanced effect on ORR activity by $\mathrm{CO}_{2}$-activated $\mathrm{B} / \mathrm{N}$ co-doped porous carbon nanosheets. Mostly, the results could be explained by integration of the large specific surface area, large pore volume ${ }^{37}$ and high N/B-doping contents of as-prepared samples. ${ }^{38}$ Actually, nitrogen as one of the most effective doping elements ${ }^{39}$ confidently enables improvement of the activity of metal-free carbon-based materials. ${ }^{40}$ Our work demonstrated that doping with different contents of $\mathrm{N}(10.4 \%$ to $5.3 \%)$ and B (2.1\% to $5.4 \%)$ essentially offered quite different catalytic activities of the resulting materials either before or after activation with $\mathrm{CO}_{2}$; thus it is quite desirable for further exploring the contribution of $\mathrm{B} / \mathrm{N}$ in such a kind of catalytic system.

Since durability is one of the major concerns in current fuel cell technology, the stability of G-CBP-a over time was tested at a constant voltage of $-0.36 \mathrm{~V}$ for $20000 \mathrm{~s}$ in a $0.1 \mathrm{M} \mathrm{KOH}$ solution saturated with $\mathrm{O}_{2}$ at a rotation rate of $1600 \mathrm{rpm}$ (Fig. 4f). Remarkably, the corresponding current-time (i-t) chronoamperometric response of G-CBP-a exhibited a fast decrease of $8 \%$ within the first $500 \mathrm{~s}$, and then a slow attenuation with a high current retention of $89 \%$ after $20000 \mathrm{~s}$. In contrast, Pt/C showed a gradual decrease, with a current loss of approximately $76 \%$ measured after $20000 \mathrm{~s}$. This suggests that the durability of G-CBP-a is superior to the commercially available Pt/C catalyst.

\section{Conclusions}

In this work, a novel $\mathrm{B} / \mathrm{N}$ co-doped porous carbon nanosheet (G-CBP-a) has been successfully prepared. Due to the large specific surface area, unique sheet nanostructure, and high heteroatom doping contents, G-CBP-a exhibited excellent electrochemical performance for the ORR under alkaline conditions $(0.1 \mathrm{M} \mathrm{KOH})$, with a low half-wave potential, a dominant four-electron transfer mechanism, and excellent methanol tolerance and durability. Further study on the controlling of the $\mathrm{B} / \mathrm{N}$ doping contents by tailoring the precursors and understanding their role in ORR will be the priority task. It is expected 
that our synthetic strategy will offer the opportunity to synthesize various heteroatom co-doped $2 \mathrm{D}$ porous carbons that will provide an important platform for developing a variety of functional devices, such as batteries, fuel cells, electronics, and sensors.

\section{Acknowledgements}

We acknowledge funding support from the Natural Science Foundation of China (NSFC 21174083), the National Basic Research Program of China (973 Program: 2012CB933404), the Shanghai Committee of Science and Technology (11JC1405400), the Shanghai Pujiang Program (12PJ1405300), and Shanghai Jiao Tong University (211 Project). Some measurements were performed in Instrumental Analysis Center of Shanghai Jiao Tong University.

\section{Notes and references}

1 R. Liu, D. Wu, X. Feng and K. Müllen, Angew. Chem., Int. Ed., 2010, 49, 2565.

2 W. Ding, Z. Wei, S. Chen, X. Qi, T. Yang, J. Hu, D. Wang, L. J. Wan, S. F. Alvi and L. Li, Angew. Chem., Int. Ed., 2013, 52, 11755.

3 Y. Zhao, C. G. Hu, Y. Hu, H. H. Cheng, G. Q. Shi and L. T. Qu, Angew. Chem., Int. Ed., 2012, 51, 11371.

4 T. P. Fellinger, F. Hasche, P. Strasser and M. Antonietti, J. Am. Chem. Soc., 2012, 134, 4072.

5 Q. Li, S. Zhang, L. Dai and L.-S. Li, J. Am. Chem. Soc., 2012, 134, 18932.

6 L. Yang, S. Jiang, Y. Zhao, L. Zhu, S. Chen, X. Wang, Q. Wu, J. Ma, Y. Ma and Z. Hu, Angew. Chem., Int. Ed., 2011, 50, 7132. 7 X. Bo and L. Guo, Phys. Chem. Chem. Phys., 2013, 15, 2459.

8 Z. Yang, Z. Yao, G. Li, G. Fang, H. Nie, Z. Liu, X. Zhou, X. A. Chen and S. Huang, ACS Nano, 2011, 6, 205.

9 R. Li, Z. D. Wei, X. L. Gou and W. Xu, RSC Adv., 2013, 3, 9978. 10 Y. Zhao, L. J. Yang, S. Chen, X. Z. Wang, Y. W. Ma, Q. Wu, Y. F. Jiang, W. J. Qian and Z. Hu, J. Am. Chem. Soc., 2013, 135, 1201.

11 Y. Zheng, Y. Jiao, L. Ge, M. Jaroniec and S. Z. Qiao, Angew. Chem., Int. Ed., 2013, 52, 3110.

12 C. H. Choi, S. H. Park and S. I. Woo, ACS Nano, 2012, 6, 7084.

13 S. B. Yang, X. L. Feng, X. C. Wang and K. Müllen, Angew. Chem., Int. Ed., 2011, 50, 5339.

14 H.-W. Liang, W. Wei, Z.-S. Wu, X. Feng and K. Müllen, J. Am. Chem. Soc., 2013, 135, 16002.

15 X. Zhuang, F. Zhang, D. Wu, N. Forler, H. Liang, M. Wagner, D. Gehrig, M. R. Hansen, F. Laquai and X. Feng, Angew. Chem., Int. Ed., 2013, 52, 9668.
16 S. Li, D. Wu, C. Cheng, J. Wang, F. Zhang, Y. Su and X. Feng, Angew. Chem., Int. Ed., 2013, 52, 12105.

17 Y. Su, Y. Zhang, X. Zhuang, S. Li, D. Wu, F. Zhang and X. Feng, Carbon, 2013, 62, 296.

18 Y. Zheng, Y. Jiao, L. Ge, M. Jaroniec and S. Z. Qiao, Angew. Chem., Int. Ed., 2013, 52, 3110.

19 S. Y. Wang, E. Iyyamperumal, A. Roy, Y. H. Xue, D. S. Yu and L. M. Dai, Angew. Chem., Int. Ed., 2011, 50, 11756.

20 S. Y. Wang, L. P. Zhang, Z. H. Xia, A. Roy, D. W. Chang, J. B. Baek and L. M. Dai, Angew. Chem., Int. Ed., 2012, 51, 4209.

21 X.-H. Li and M. Antonietti, Angew. Chem., Int. Ed., 2013, 52, 4572.

22 D. Wu, F. Zhang, H. Liang and X. Feng, Chem. Soc. Rev., 2012, 41, 6160.

23 X. Huang, X. Qi, F. Boey and H. Zhang, Chem. Soc. Rev., 2012, 41, 666.

24 J. Wu, W. Pisula and K. Müllen, Chem. Rev., 2007, 107, 718. 25 L. Dai, Acc. Chem. Res., 2012, 46, 31.

26 Y.-F. Lu, S.-T. Lo, J.-C. Lin, W. Zhang, J.-Y. Lu, F.-H. Liu, C.-M. Tseng, Y.-H. Lee, C.-T. Liang and L.-J. Li, ACS Nano, 2013, 7, 6522.

27 G. Wu, K. L. More, C. M. Johnston and P. Zelenay, Science, 2011, 332, 443.

28 Y.-W. Cheng, L. Chao, Y.-M. Wang, K.-S. Ho, S.-Y. Shen, T.-H. Hsieh and Y.-Z. Wang, Synth. Met., 2013, 168, 48.

29 W. S. Hummers and R. E. Offeman, J. Am. Chem. Soc., 1958, 80, 1339.

30 G. Li and Z. Zhang, Macromolecules, 2004, 37, 2683.

31 S. H. Brewer, A. M. Allen, S. E. Lappi, T. L. Chasse, K. A. Briggman, C. B. Gorman and S. Franzen, Langmuir, 2004, 20, 5512.

32 L. Liu, Q.-F. Deng, X.-X. Hou and Z.-Y. Yuan, J. Mater. Chem., 2012, 22, 15540.

33 M. Saleh, V. Chandra, K. C. Kemp and K. S. Kim, Nanotechnology, 2013, 24, 255702.

34 E. Pringsheim, E. Terpetschnig, S. A. Piletsky and O. S. Wolfbeis, Adv. Mater., 1999, 11, 865.

35 Y. Zhang, K. Fugane, T. Mori, L. Niu and J. Ye, J. Mater. Chem., 2012, 22, 6575.

36 Y. Tang, B. L. Allen, D. R. Kauffman and A. Star, J. Am. Chem. Soc., 2009, 131, 13200.

37 Z. Zuo, Z. Jiang and A. Manthiram, J. Mater. Chem. A, 2013, 1, 13476.

38 S. Yasuda, L. Yu, J. Kim and K. Murakoshi, Chem. Commun., 2013, 49, 9627.

39 P. Matter and U. Ozkan, Catal. Lett., 2006, 109, 115-123.

40 W. Wei, H. Liang, K. Parvez, X. Zhuang, X. Feng and K. Müllen, Angew. Chem., Int. Ed., 2013, 53, 1570. 